\title{
SISTEM AKUISISI DATA BERBASIS ARDUINO PADA REKAYASA PROTOTIPE SHELL AND TUBE HEAT EXCHANGER
}

\author{
Haolia Rahman ${ }^{1}$, Candra Damis Widiawaty ${ }^{2}$, Hamdi $^{3}$, \\ Eko Nugroho Setijogiarto ${ }^{4}$ \\ 1,2,3,4 Jurusan Teknik Mesin, Politeknik Negeri Jakarta \\ ${ }^{\circledR}$ Email: haolia.rahman@mesin.pnj.ac.id
}

\begin{abstract}
Common method to measure the performance of the shell and tube heat exchanger is the log mean temperature different (LMTD) method. The LMTD method requires the temperature at the inlet and outlet of the shell and tube. For this reason, the data acquisition system was built to measure the temperature at the required points in real-time. In addition, a flow meter is installed to measure flow rate at the shell and the tube inlet, where the overall heat transfer from the heat exchanger can be obtained. The Arduino board was used as a data acquisition system for the observed heat exchanger. The results of this study are a data acquisition system to measure the performance of prototype shell and tube. Based on the measurement results with a flow rate variation of $6 \mathrm{~L} / \mathrm{s}$ and $2 \mathrm{~L} / \mathrm{s}$, the average $\mathrm{LMTD}$ is $15.31^{\circ} \mathrm{C}$ ).
\end{abstract}

Keywords: shell and tube, Arduino, log mean temperature different, data acquisition

\begin{abstract}
Abstrak
Metode umum yang biasa digunakan mengukur kinerja alat penukar kalor (APK) tipe shell and tube, adalah metode log mean temperature different (LMTD). Pada metode LMTD, temperatur pada sisi masuk dan keluar shell and tube perlu diketahui. Untuk itu, sistem data akusisi yang dibuat pada penelitian ini ditujukan untuk dapat mengukur temperatur pada titik-titik yang dibutuhkan secara realtime. Selain itu, flow meter dipasang untuk mengukur laju aliran fluida yang masuk pada sisi shell dan tube, sehingga perpindahan panas secara keseluruhan dari APK dapat diperoleh. Perangkat Arduino digunakan sebagai sistem data akusisi pada APK yang diobservasi. Hasil dari penelitian ini berupa sistem data akusisi untuk mengukur performa prototype APK shell and tube. Berdasarkan hasil pengukuran data akuisisi tersebut dengan variasi laju aliran $6 \mathrm{~L} / \mathrm{s}$ dan $2 \mathrm{~L} / \mathrm{s}$ diperoleh nilai LMTD ratarata sebesar $15,31^{\circ} \mathrm{C}$.
\end{abstract}

Kata kunci: shell and tube, Arduino, log mean temperature different, data akuisisi

\section{Pendahuluan}

Alat penukar kalor (APK) tipe shell and tube merupakan APK yang paling banyak digunakan di industri proses saat ini. Hal ini dikarenakan memiliki effisiensi yang tinggi, dapat mengakomodasi ekspansi termal, mudah untuk dibersihkan, dan konstruksi yang relatif lebih sederhana dibanding dengan APK jenis lain [1]. Masalah umum yang terjadi pada APK salah satu nya adalah fouling [2]. Fouling atau kerak pada dinding shell and tube dapat diketahui dari performa APK yang menurun setelah beroperasi dalam kurun waktu tertentu. Untuk mengetahui performa APK, metode umum yang paling banyak digunakan adalah metode log mean temperature different (LMTD) [3]. Input parameter yang dibutuhkan untuk menentukan nilai $L M T D$ adalah dengan mengukur temperatur pada sisi masuk dan keluar shell dan tube.

Data logger pada sistem APK shell and tube telah digunakan oleh Shirari dkk.[4]. Namun, data loger tersebut digunakan untuk mengetahui penomena perubahan temperatur di dalam tube bukan kinerja APK shell and tube secara keseluruhan. El-Saida dan Al-Sood menggunakan Arduino dalam pengukuran temperatur 
dan tekanan pada APK shell and tube[5]. Arduino merupakan interface elektronik yang dapat berfungsi sebagai data logger, kendali kontrol serta prosessor sederhana. Dengan software open source yang memiliki library-nya masingmasing.

Penelitian ini merupakan perancangan sistem DAQ pada alat penukar kalor tipe shell and tube untuk mengetahui kinerja alat melalui metode LMTD. Jumlah sensor temperatur disesuaikan dengan kebutuhan objek yang akan diobservasi.

\section{Metode Penelitian}

\section{Perangkat APK shell and tube}

Sistem pengujian dari APK shell and tube dirangkai seperti terlihat pada gambar 1 . Tahapannya, hot fluid (HF) awalnya berada di tangki $H F 1$ lalu dialirkan oleh pompa menuju tangki $H F 2$ di bagian atas. Pada bagian tangki atas ini, $H F$ dipanaskan menggunakan pemanas elektrik yang dikontrol secara otomatis dengan batas atas pemasanasan sebesar $60^{\circ} \mathrm{C}$. Aliran $H F$ memasuki inlet tube

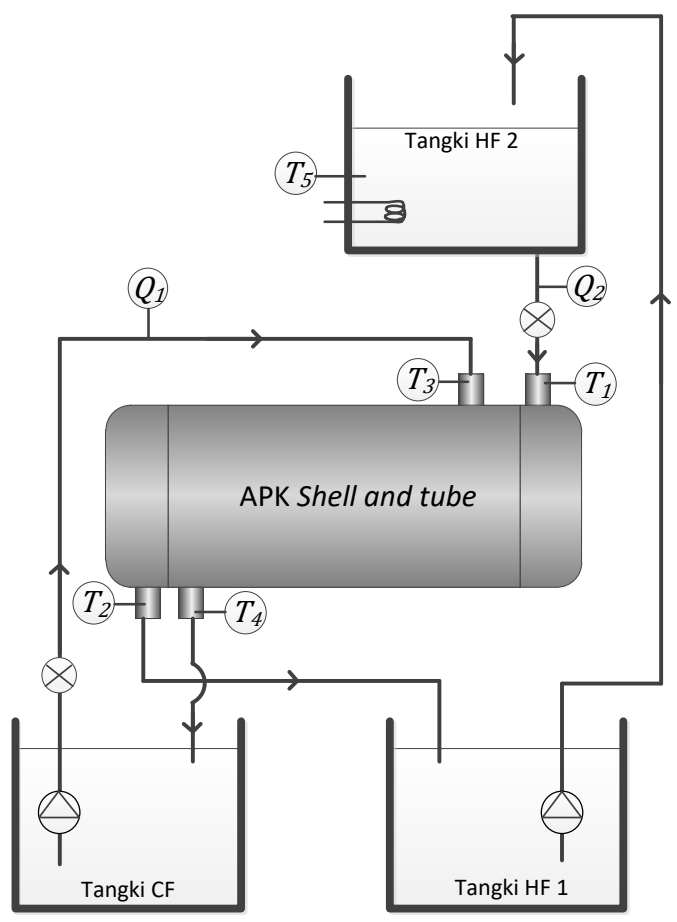

Gambar 1. Skema sistem pengujian APK Shell and Tube. yang temperatur dan debitnya diukur oleh thermocouple $\left(T_{1}\right)$ dan flowmeter $\left(Q_{1}\right)$. Selanjutnya, $H F$ keluar dari shell diukur oleh thermocouple $\left(T_{2}\right)$ dimana alirannya menuju tangki $H F 2$. Siklus aliran $H F$ ini akan terus berlanjut saat proses berlangsung. Disisi aliran dingin, cool fluid $(C F)$ dialirkan oleh pompa menuju inlet shell dan diukur temperatur dan debitnya melalui thermocouple $\left(T_{3}\right)$ dan flowmeter $\left(Q_{1}\right)$. Aliran $C F$ kemudian keluar pada sisi shell dan diukur temperaturnya menggunakan thermocouple $\left(T_{4}\right)$ menuju tangki $\mathrm{CF}$.

\section{Data Aqusisi APK Shell and Tube}

Data aqusisi (DAQ) pada perangkat APK shell and tube digunakan untuk mengukur parameter-parameter yang digunakan dalam penentuan efisiensi APK. Parameter tersebut diantaranya adalah temperatur masuk dan keluar shell dan tube $\left(T_{1}, T_{2}, T_{3}\right.$, dan $\left.T_{4}\right)$, serta flow meter sisi masuk shell dan sisi masuk tube $\left(Q_{1}\right.$ dan $\left.Q_{2}\right)$. Sensor temperatur yang digunakan adalah thermocouple tipe- $\mathrm{K}$ dengan error yang tertera dari manufaktur sebesar $\pm 2^{\circ} \mathrm{C}$. Sedangkan flowmeter yang digunakan adalah tipe YF-S201 dengan kapasitas pengukuran aliran 1-30 L/s.

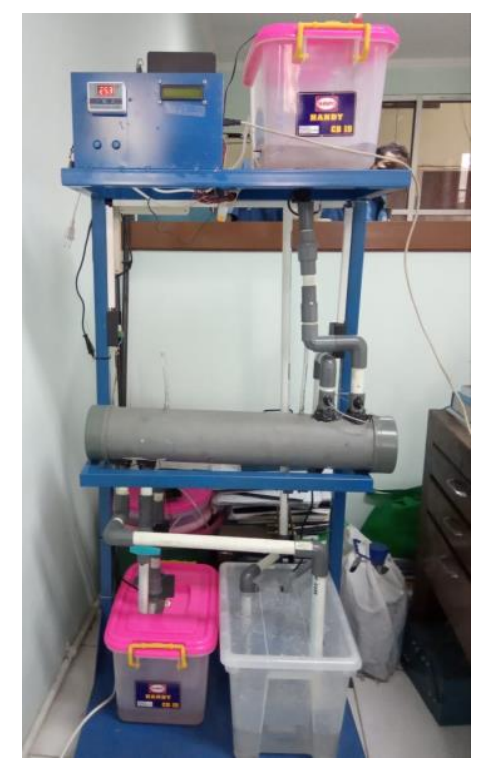

Gambar 2. Sistem data logger yang dipasang pada Prototipe APK shell and tube 
Mikrokontroller yang terpasang adalah Arduino Mega yang berperan sebagai data logger atau DAQ. Memori modul digunakan sebagai perangkat penyimpan data menggunakan $S D$ card, dan layar LCD 16 x 2 digunakan sebagai perangkat sajian data yang dapat dibaca secara realtime. Pemrograman DAQ ini menggunakan perangkat lunak Arduino 1.8.13.

\section{Laju perpindahan kalor pada APK shell and tube}

Laju perpindahan kalor $(Q)$ dalam Watt pada APK shell and tube dapat di formulasikan seperti pada persamaan 1[6]. Dimana, $U$ merupakan koefisien perpindahan kalor keseluruhan dalam $\mathrm{W} / \mathrm{m}^{2} .{ }^{\circ} \mathrm{C}$. Luas penampang dari APK dinotasikan dalam $A$ dan LMTD merupakan perbedaan temperatur ratarata logaritma dalam ${ }^{\circ} \mathrm{C}$. Jenis aliran yang digunakan pada penelitian ini adalah tipe parallel[7] sehingga LMTD pada aplikasi APK ini dapat dirumuskan seperti pada persamaan 2 .

$$
\begin{aligned}
& Q=U \times A \times L M T D \\
& L M T D=\frac{\left(T_{3}-T_{1}\right)-\left(T_{4}-T_{2}\right)}{\ln \frac{\left(T_{3}-T_{1}\right)}{\left(T_{4}-T_{2}\right)}}
\end{aligned}
$$

\section{Hasil dan Pembahasan}

\section{Prototipe APK shell and tube dan data logger}

Data logger yang dirakit pada prototipe APK seperti terlihat pada gambar 2. Hasil pengukuran temperatur inlet dan outlet pada sisi shell dan tube $\left(T_{1}, T_{2}, T_{3}\right.$ dan $\left.T_{4}\right)$ dapat terlihat pada layar LCD. Begitu pula dengan nilai $L M T D$ dan laju aliran masing-masing inlet $Q_{1}$ dan $Q_{2}$ seperti ditunjukkan oleh gambar 3. Laju aliran dapat diatur melalui pengaturan katup pada sisi inlet dan outlet tube. Sehingga pada percobaan ini data performa APK yang digunakan adalah pada laju aliran 6

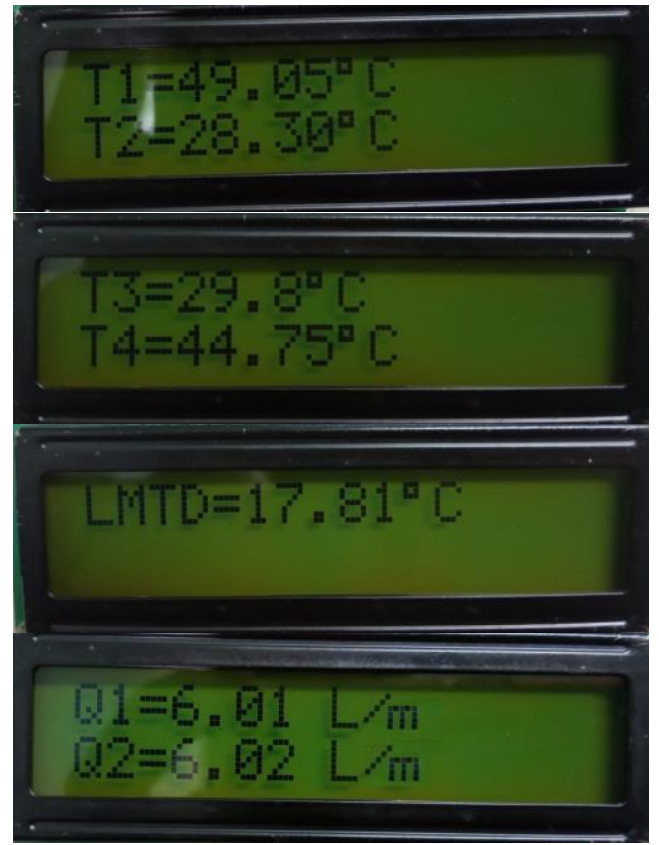

Gambar 3. Diplay LCD dari pengukuran performa APK

$\mathrm{L} / \mathrm{min}$ dan $2 \mathrm{~L} / \mathrm{min}$ yang terbaca pada flow meter.

\section{Pengukuran performa APK}

Pengukuran performa APK terukur melalui koefisien perpindahan panas $U$ dimana indeks ini terukur dari nilai LMTD. Untuk menentukan nilai $L M T D$, temperatur pada tiap inlet outlet shell dan tube diukur dengan menggunakan data logger seperti terlihat pada gambar 4 dengan laju aliran $6 \mathrm{~L} / \mathrm{min}$ dan gambar 5 untuk laju aliran $2 \mathrm{~L} / \mathrm{min}$.

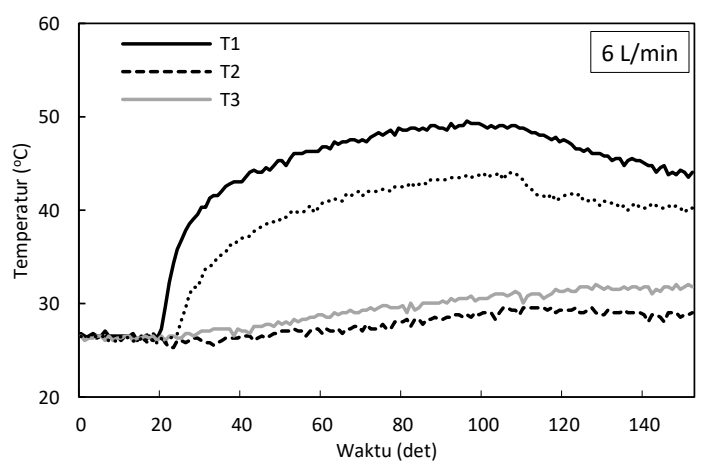

Gambar 4. Data temperatur pada inlet outlet shell and tube dengan laju aliran $6 \mathrm{~L} / \mathrm{min}$ 


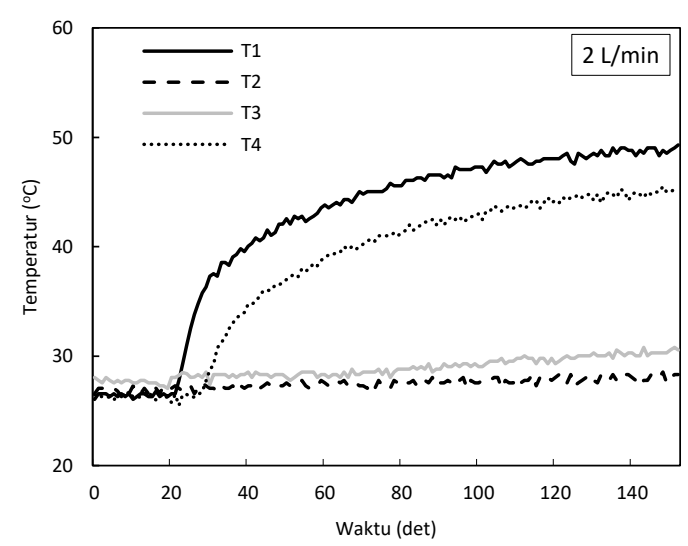

Gambar 5. Data temperatur pada inlet outlet shell and tube dengan laju aliran $2 \mathrm{~L} / \mathrm{min}$

Dari kedua gambar tersebut terlihat bahwa tren temperatur masuk pada sisi tube $\left(T_{1}\right)$ naik secara eksponensial dan pola yang sama juga terbentuk pada temperatur sisi keluar tube $\left(T_{2}\right)$ dengan selisih temperatur yang menandakan APK shell and tube ini berkerja dengan baik. Begitu pula pada trend temperatur masuk dan keluar sisi shell yang diwakili oleh titik $T_{3}$ dan $T_{4}$ mengalami perbedaan temperatur setelah melewati dinding tube.

Tabel 1 menunjukan performa dari APK untuk percobaan pada laju aliran $6 \mathrm{~L} / \mathrm{min}$ dan $2 \mathrm{~L} / \mathrm{min}$. Dari tabel terlihat bahwa jumlah sample pada aliran $2 \mathrm{~L} / \mathrm{min}$ lebih banyak dari jumlah sample pada laju aliran $6 \mathrm{~L} / \mathrm{min}$. Jumlah sample yang diukur tiap detiknya mengacu pada stok volume $H F$ yang terdapat pada tangki $H F 2$ sehingga pada laju aliran $2 \mathrm{~L} / \mathrm{min}$ mempunyai jumlah sample lebih banyak. Dari kedua pengujian tersebut diperoleh bahwa nilai $L M T D$ hampir memiliki nilai kesamaan dengan nilai rata-rata keduanya sebesar $15,31^{\circ} \mathrm{C}$.

Tabel 1. Pengukuran LMTD menggunakan data logger

\begin{tabular}{lrr}
\hline & \multicolumn{2}{c}{ Laju aliran } \\
\cline { 2 - 3 } & 6 L/min & 2 L/min \\
\hline Jumlah sample & 124 & 260
\end{tabular}

\begin{tabular}{lrr}
$\begin{array}{l}L M T D \text { rata- } \\
\text { rata }\left({ }^{\circ} \mathrm{C}\right)\end{array}$ & 14,52 & 16,10 \\
$\begin{array}{l}\text { Standar deviasi } \\
L M T D\left({ }^{\circ} \mathrm{C}\right)\end{array}$ & 1,94 & 2,37 \\
\hline
\end{tabular}

\section{Kesimpulan}

Sistem akusisi data pada alat penukar kalor ini telah berhasil dilakukan sehingga performanya dapat langsung di lihat pada layar yang terpasang. Selain itu, sistem ini berfungsi sebagai data loger sehingga temperatur pada masingmasing sisi inlet dan outlet dari shell dan tube dapat tersimpan. Metode log mean temperatur difference digunakan untuk mengetahui koefisien perpindahan panas keseluruhan dari alat penukar kalor.

\section{Ucapan Terima Kasih}

Ucapan terima kasih kepada UP2M PNJ. Penelitian ini dibiayai oleh DIPA Politeknik Negeri Jakarta Dengan nomor kontrak B.198/PL3.18/PN.00.03/2020.

\section{Daftar Pustaka}

[1] S Kakaç, H Liu, Heat Exchangers: Selection, Rating and Thermal Design (2nd ed.). CRC Press. ISBN 0-8493-0902-6. 2002.

[2] W Ebert, CB Panchal, Analysis of exxon crude-oil-slip-stream coking data, in: Proceedings of Fouling Mitigation of Industrial HeatExchanger Equipment, California, USA, 1995.

[3] F Ahmad, Alternative Approach for Determining Log Mean Temperature Difference Correction Factor and Number of Shells of Shell and Tube Heat Exchangers, Journal of Enhanced Heat Transfer, Vol. 10 (4), PP 407-420, 2003.

[4] PSVV Srihari, PSVVS Narayana, VH Kumar, VSS Prakash, P Jaikishan, Experimental study on a shell and tube heat exchanger with 
novel self agitating inserts, AIP Conference Proceedings 2200, 020039, 2019.

[5] Shell and tube heat exchanger with new segmental baffles configurations: A comparative experimental investigation Emad M.S. El-Saida , M.M. Abou AlSoodb, Applied Thermal Engineering, Vol. 150, 2019, 803810, 2019.

[6] I Bizzy, R Setiadi, Studi perhitungan alat penukar kalor tipe shell and tube dengan program heat transfer research inc. ( HTRI), Jurnal Rekayasa Mesin, Vol. 13 No. 1, 2013.

[7] CD Widiawaty, GGR Gunadi, A Syuriadi, Pemodelan dan analisis kinerja shell and tube heat exchanger dengan metode CFD, Politeknologi, Vol. 16 No. 3, 2017. 